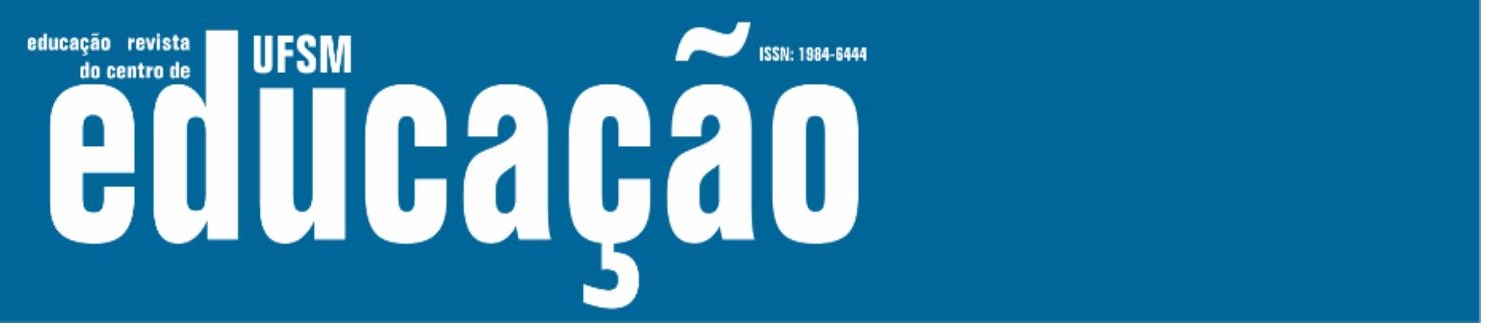

ISSN: 1984-6444 | http://dx.doi.org/10.5902/1984644464258

\title{
Encontros e desencontros entre professores e o ensino remoto emergencial
}

\author{
Encounters and dis-encounters between teachers and emergency \\ remote education
}

\section{Encuentros y desencuentros entre profesores y la enseñanza remota emergencial}

\section{Lara Carlette Thiengo}

Professora Doutora na Universidade Federal dos Vales do Jequitinhonha e Mucuri. Diamantina, Minas Gerais, Brasil.

laracarlette@gmail.com - https://orcid.org/0000-0003-3593-4746

Maria Fernanda Diogo

Professora Doutora na Universidade Federal de Santa Catarina. Florianópolis, Santa Catarina, Brasil. mafediogo@gmail.com - http://orcid.org/0000-0002-5936-0823

\section{Lucídio Bianchetti}

Professora Aposentado/Voluntário na Universidade Federal de Santa Catarina. Florianópolis, Santa Catarina, Brasil.

lucidiob@gmail.com - http://orcid.org/0000-0001-9748-5646

Kaue Tortato Alves

Doutorando na Universidade Federal de Santa Catarina. Florianópolis, Santa Catarina, Brasil.

k.tortato@ufsc.br - http://orcid.org/0000-0002-1374-4311

Neiva de Assis

Professora Doutora na Universidade Federal de Santa Catarina. Florianópolis, Santa Catarina, Brasil. neivapsi2016@gmail.com - http://orcid.org/0000-0002-5530-2095

Recebido em 14 de fevereiro de 2021

Aprovado em 11 de junho de 2021

Publicado em 04 de setembro de 2021

\section{RESUMO}

Em meados de março de 2020 ocorreu a suspensão das atividades educacionais presenciais nas redes de ensino pública e privada, em decorrência do afastamento social provocado pela pandemia de Covid-19, motivo pelo qual as instituições educacionais tornaram-se adeptas do ensino remoto emergencial (ERE). Considerando este cenário, ainda em movimento, este texto busca: 1) apresentar trabalhos desenvolvidos por pesquisadores de diferentes países neste curto espaço de tempo, no intuito de entender o que representou a suspensão das atividades escolares presenciais e a continuidade do calendário via ERE; e 2) apresentar dados 


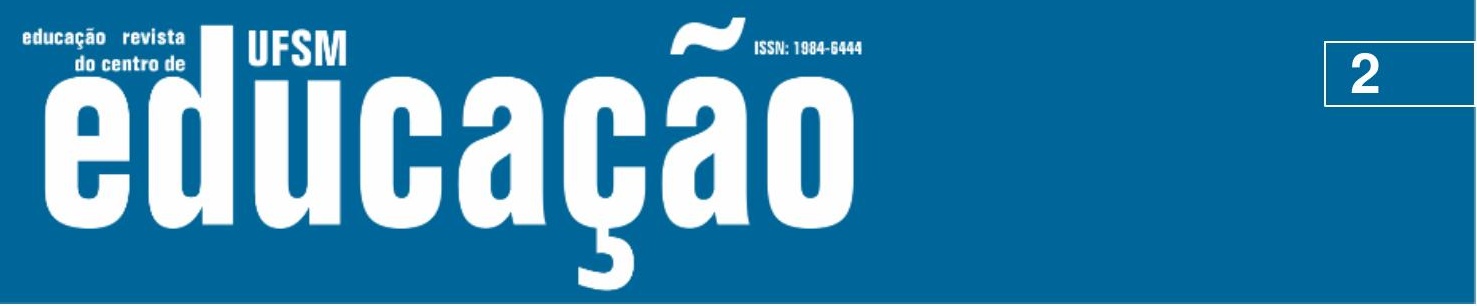

ISSN: 1984-6444 | http://dx.doi.org/10.5902/1984644464258

de pesquisa de campo desenvolvida com professores da Educação Básica e Superior, na qual participaram 321 docentes de 14 Estados brasileiros. Por meio da aplicação de questionários digitais investigou-se, junto a esses professores, suas experiências, desafios, sentimentos, reflexões e como se objetivava a docência em formato remoto. Evidenciaram-se depoimentos de descontentamento e impotência frente às condições atuais do trabalho docente, grande angústia relacionada à aprendizagem dos estudantes e, também, relatos de esforços individuais e coletivos em prol de ações pedagógicas que desenvolvam o ERE do melhor modo possível.

Palavras-chave: Ensino Remoto Emergencial; Covid-19; Trabalho Docente.

\section{ABSTRACT}

In mid-March 2020 classroom educational activities were suspended in public and private school systems due to the need for social distancing provoked by the Covid-19 pandemic. For this reason, educational institutions became adept at emergency remote education (ERE). Considering this situation, which is still in progress, this text: 1) presents studies conducted by researchers from various countries in this brief space of time, to understand the suspension of classroom school activities and the continuity of the school calendar via emergency remote education; and 2) to present data from field research conducted with schoolteachers and university professors, in which 321 teachers participated from 14 Brazilian states. By issuing digital questionnaires, the study sought to learn about the experiences, challenges, feelings, and reflections of these teachers and how they conducted remote teaching. Statements expressing discontent and impotence were found in relation to the current teaching conditions, and tremendous anguish related to students' learning. There are also reports of individual and collective efforts to support pedagogical actions that made the best of Emergency Remote Education

Keywords: Emergency Remote Education; Covid-19; The Work of Teaching

\section{RESUMEN}

A mediados de marzo de 2020 se han suspendido las actividades educativas presenciales en las redes educativas públicas y privadas, debido al alejamiento social provocado por la pandemia del Covid-19, razón por la cual las instituciones educativas se volvieron adeptas a la Educación Remota de Emergencia (ERE). Considerando este escenario, aún en marcha, este texto busca: 1) presentar trabajos desarrollados por investigadores de diferentes países en este corto período de tiempo, con el fin de comprender en qué consistió la suspensión de las actividades del aula y la continuidad del calendario vía ERE; y 2) presentar datos de investigación de campo desarrollada con profesores de Educación Básica y Superior, en la que participaron 321 profesores de 14 estados brasileños. Mediante la aplicación de cuestionarios digitales, investigamos, junto a estos docentes, sus vivencias, desafíos, sentimientos, 


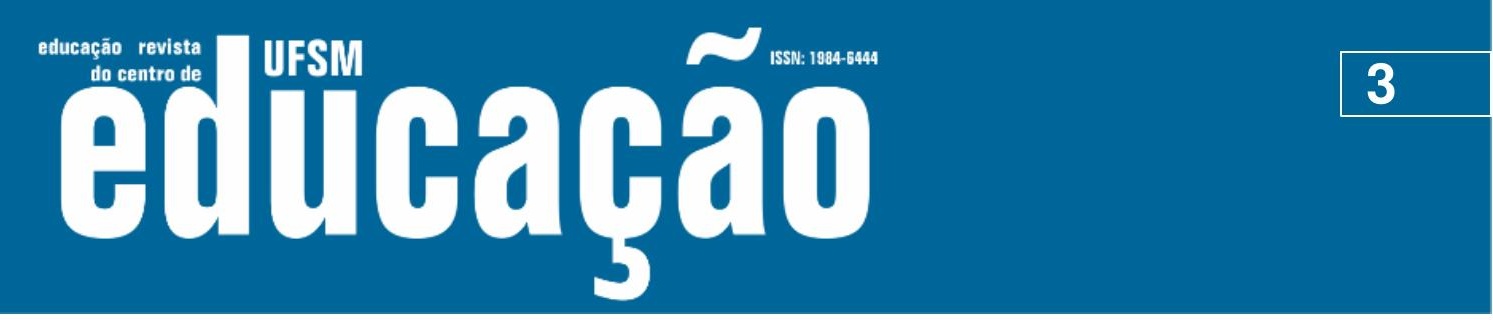

ISSN: 1984-6444 | http://dx.doi.org/10.5902/1984644464258

reflexiones y cómo se objetivaba la enseñanza remota. Hubo deposiciones de descontento e impotencia ante las actuales condiciones de trabajo docente, gran angustia relacionada con el aprendizaje de los estudiantes, y también relatos de esfuerzos individuales y colectivos a favor de acciones pedagógicas que desarrollen la ERE de la mejor manera posible.

Palabras-clave: Enseñanza Remota de Emergencia;; Covid-19; Trabajo Docente

\section{Introdução}

No momento em que escrevemos este artigo, completamos dez meses de pandemia de Covid-19 (Sars-Cov-2). No âmbito legal, este período foi marcado por decretos, ora de âmbito federal, ora estadual ou municipal. Fomos testemunhas e participantes, muitas vezes surpreendidos e perplexos, de um constante abre e fecha das atividades econômicas, dos espaços educacionais e de lazer, dentro do que passamos a denominar afastamento social, expressão gerada por esta situação atípica. Contabilizamos, nestes dez meses de pandemia, 92 milhões de casos de infecção no mundo (OPAS, 2020), sendo oito milhões duzentos e sessenta mil deles, no Brasil (PAINEL CORONAVÍRUS, 2020).

Entre meados de março e início de abril, escolas de Educação Básica (EB) e Instituições de Ensino Superior (IES) brasileiras suspenderam as atividades presenciais. Naquele momento a expectativa era de quarentena, ou seja, afastamento social por alguns meses. Contudo, a perspectiva da rápida retomada das atividades letivas presenciais esbarrou no número crescente de mortos pela Covid-19. Em 13 de janeiro de 2021, contabilizávamos, no Brasil, 206.063 (PAINEL CORONAVÍRUS, 2020).

Em abril, o Conselho Nacional de Educação (CNE) emitiu o Parecer $n^{\circ}$ 5/2020 favorável às atividades pedagógicas não presenciais computadas para fins de cumprimento da carga horária anual mínima. O órgão destacou que as atividades poderiam ser desenvolvidas por meios digitais (videoaulas, conteúdos organizados em plataformas virtuais de ensino e aprendizagem, redes sociais, correio eletrônico, entre outros), por meio de programas de televisão ou rádio, pela adoção de material didático impresso com orientações pedagógicas, distribuído aos estudantes e pela 


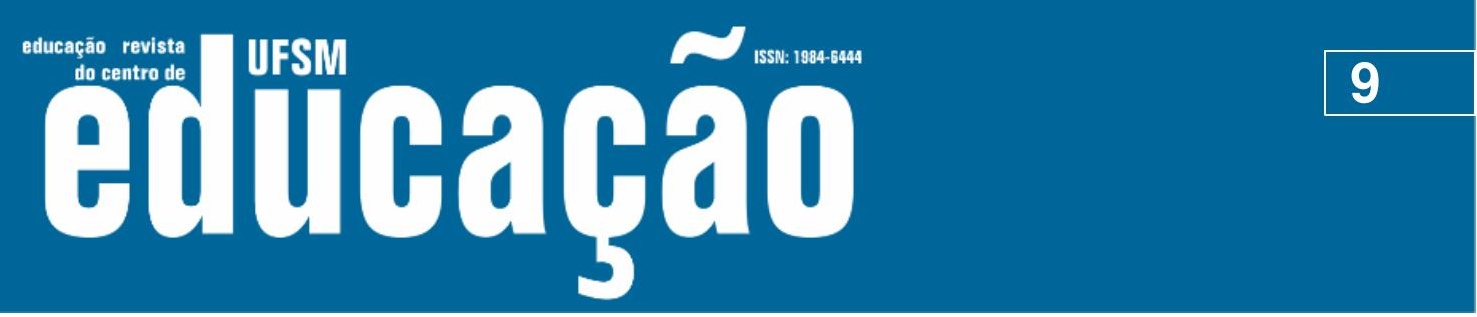

ISSN: 1984-6444 | http://dx.doi.org/10.5902/1984644464258

As soluções mágicas, das quais o professor parece ser mero instrumento, explodiram: aulas pela TV local; videoaulas por redes sociais; aulas on-line; plataformas on-line; materiais digitais para professor e aluno; uso de redes sociais; tutoria on-line; tarefas por whatsapp; podcast; kits; blogs; bancos de aulas prontas, aplicativos, apoio psicológico por mensagem. $\mathrm{Na}$ porta entreaberta do debate pulavam de alegria os "parceiros": emissoras de televisão e telefonia, organizações comunitárias, setor privado de tecnologia, emissoras de rádio, consultores com seus pacotes de aprendizagem digitais ou impressos. (FIEIRA, EVANGELISTA e FLORES, 2020, p. 27).

Ainda segundo as autoras, existe uma verba do Governo Federal aprovada para aquisição de soluções tecnológicas para as escolas públicas, o que abriria possibilidades para a efetivação da educação mediada por tecnologia no currículo escolar do pós-pandemia. Nesta mesma linha de análise, Leher (2020) aponta que a maioria das plataformas educacionais utilizadas pelas redes públicas é comandada por cinco grandes corporações (Amazon, Microsoft, Facebook, Apple, Alphabet/Google), as quais possuem objetivos estratégicos para a edificação de um mercado mundial de educação. Neste sentido, a pandemia alavancou a ampliação de mercados. Pichetti (2020, p. 1) afirma: "o ensino remoto não é, de fato, emergencial, mas emergente". Segundo a autora, o ensino híbrido, que combina práticas presenciais e remotas, já vinha sendo anunciado como um modelo a ser perseguido pelas universidades. A autora indaga:

[...] se o Ensino Remoto é "emergencial", qual é a emergência que estamos enfrentando? Parece que a resposta mais otimista é que a emergência está em "socorrer" o semestre ou o calendário acadêmico. Contudo, se essa é a nossa resposta otimista é porque existe uma resposta de fato "pior" que a já inaceitável subordinação da formação à certificação. Parece que a verdadeira emergência do Ensino Remoto está em gestar as bases, objetivas e subjetivas, para uma implementação sistemática e permanente da lógica remota de organização da atividade pedagógica nas Universidades públicas. (PICHETTI, 2020, p. 1, destaque da autora)

No bojo desta discussão está a mercantilização do ensino remoto. Hodges et al (2020, p. 10) apontam para "[...] o movimento de gestores em busca de soluções robustas, completas e complexas de EaD", bem como "empresas e fornecedores que aproveitam este momento de fraqueza do sistema para penetrar pelos flancos dos muros das escolas com plataformas, serviços e soluções complexas demais para serem imediatamente e emergencialmente utilizadas". 


\section{تilfoarẫ}

ISSN: 1984-6444 | http://dx.doi.org/10.5902/1984644464258

Williamson, Eynon e Potter (2020, p. 106) levantam críticas às afirmações simplistas e oportunistas de que as tecnologias são o remédio para a crise educacional. Os autores afirmam ser necessário desenvolver pesquisas que "examinem, em detalhes, os efeitos e consequências da expansão e incorporação de tecnologias digitais e mídia em sistemas de educação, instituições e práticas através do mundo". Estas não são questões novas ou exclusivas da pandemia, mas "estão sendo vivenciadas de forma mais intensa e efetiva por professores, estudantes e pais em todo o mundo, dos primeiros anos de escolarização até o ensino superior" (WILLIAMSON; EYNON; POTTER, 2020, p. 107).

Citando a Global Education Coalition - parceria internacional destinada a mobilizar recursos e implementar soluções inovadoras para ampliar globalmente a educação online - os autores destacam a formação de coalizões e redes que buscam promover "uma resposta de curto prazo à pandemia e uma ambição de longo prazo para sistemas educacionais inteiros" (WILLIAMSON; EYNON; POTTER, 2020, p. 108). As parcerias aliam empresas como Google, Microsoft, Facebook e Zoom a organizações internacionais, como a OCDE e o Banco Mundial. É importante frisar que estas organizações, na condição de intelectuais coletivos do capital, são responsáveis pela produção de materiais, diagnósticos e orientações no sentido de promover consensos sobre a viabilidade da privatização e do aprofundamento da diferenciação educacional. Williamson, Eynon e Potter (2020) apontam que o Banco Mundial atua junto a governos em todo o mundo com vistas a estabelecer a educação online, enquanto a OCDE tem associado à Covid-19 a uma crise de desenvolvimento de "capital humano". Para os autores, estas organizações influenciam a elaboração de políticas há décadas e abrem espaço para plataformas privadas estenderem seu alcance a territórios anteriormente inatingíveis, como por exemplo, a Educação Infantil.

Cunha, Silva, A e Silva, A (2020) discutiram os resultados de pesquisa documental sobre a qualidade e o direito do acesso à educação a partir da organização do trabalho escolar pelas secretarias estaduais de educação no contexto da pandemia. Os autores apresentaram a organização do trabalho escolar de cada unidade federativa do Brasil com vistas ao Parecer do CNE no 5/2020 e discutiram 


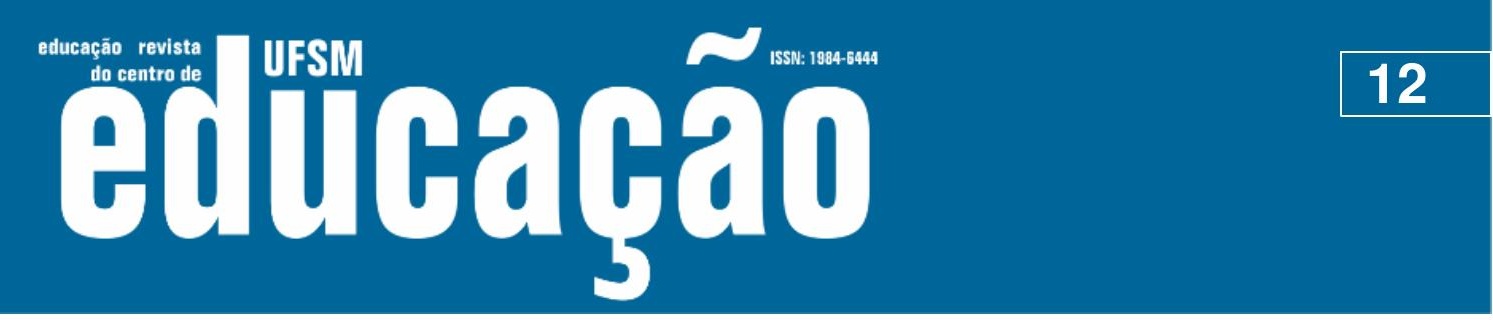

ISSN: 1984-6444 | http://dx.doi.org/10.5902/1984644464258

período e, das que seguiram trabalhando de forma remunerada, $41 \%$ relataram intensificação do trabalho, "[...] com sobreposições de responsabilidades do trabalho remunerado, do trabalho doméstico e de cuidados, uma realidade que, de acordo com $61,5 \%$ das mulheres, dificulta o trabalho remunerado" (SEMPREVIVA, 2020, p. 27). Para perscrutar o trabalho das professoras que se dedicaram ao ERE esta realidade precisa ser considerada.

Por fim, além de intensificado, o discurso sobre o trabalho docente teria sofrido uma espécie de simplificação uma vez que, como afirma Pichetti (2020), o professor não seria mais o responsável por ensinar, mas aquele que acompanha aprendizagens. Trata-se de uma

[...] lógica de transformação do trabalho vivo docente por trabalho morto (a aula transforma-se em "vídeo-aula"; o ensino transforma-se em "atividade assíncrona"); e a lógica de redução das metas ou expectativas formativas (redução dos conteúdos, da carga de leitura e, sobretudo, da possibilidade de profundidade no trato com o conhecimento). (PICHETTI, 2020, p.1)

São exemplos desta lógica: a diminuição do tempo de aulas, a redução da quantidade de leituras e conteúdos, das expectativas docentes sobre as aprendizagens dos estudantes e a busca por "soluções" para problemas que possivelmente aparecerão no pós-pandemia (especialmente em um cenário de redução de financiamento e de autonomia). A autora aponta que estes são "pontos sensíveis" para refletirmos "além do [nosso] próprio umbigo" (PICHETTI, 2020, p.1).

\section{O ensino remoto emergencial nos relatos dos docentes}

Nesta seção discutimos dados levantados na pesquisa exploratória "O novo "Normal"? Sentidos atribuídos ao ensino remoto por professores/as da Educação Básica e Superior" (Aprovado pelo Comitê de Ética e Pesquisa da UFSC/ 31218620.6.0000.0121) realizada junto a professores que atuam em redes de ensino e instituições públicas e privadas, no Brasil. Com a pesquisa objetivamos compreender os sentidos atribuídos ao ERE e identificar as condições - materiais e simbólicas - em que são desenvolvidas as atividades não presenciais. Dividimos a 


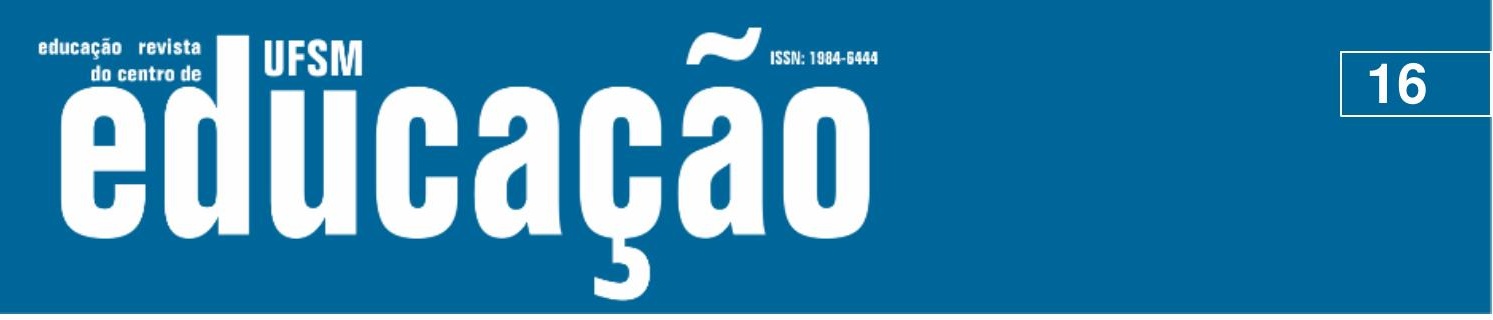

ISSN: 1984-6444 | http://dx.doi.org/10.5902/1984644464258

qualificação ou de apoios para desenvolverem o ERE, apontando, inclusive, bons resultados. Destacamos o depoimento de uma professora que, ao refletir sobre sua experiência, trouxe uma descrição detalhada do seu dia a dia. Este relato é representativo porque agrega elementos emergentes em diversos outros discursos: a sensação de despreparo frente ao desconhecido, os apoios encontrados, a formação recebida, as ferramentas do trabalho remoto, o cotidiano intenso, os aprendizados realizados no percurso, as frustrações e as preocupações. Pelo seu teor representativo, não foram realizados cortes.

\begin{abstract}
Um grande desafio. Durante este tempo errei inúmeras vezes. $\mathrm{Na}$ verdade, erramos. Trabalho com o ensino fundamental na turma do $3^{\circ}$ ano. Na escola em que trabalho, eu e minhas outras colegas do terceiro ano decidimos nos unir, criar um grupo e fazer juntas todos os planejamentos. Assim que foi inserido o ensino digital, em abril, nós criamos grupos de WhatsApp das turmas, gravamos vídeos e explicamos como iria acontecer. Utilizamos o classroom e o WhatsApp. As famílias foram bem resistentes ao uso da plataforma. Explicamos a elas que o WhatsApp é um meio informal e a plataforma oficializa os envios. No entanto, não podemos deixar para trás aquelas famílias que não têm computador e esse aplicativo acaba facilitando. Algumas famílias pegam material impresso na Escola, realizam as atividades e nos mandam por fotos. Durante este tempo buscamos acima de tudo acolher. Quando digo que erramos é pela questão de no começo enviar muitas atividades e conteúdo. Hoje tentamos equilibrar, pois sabemos que a criança não aprende pela quantidade e sim pela qualidade. Hoje estamos aprendendo, gravamos vídeos, fazemos videoaulas pelo meet e até ligações se for preciso. O Estado disponibilizou webinares [sic, seminário online, transmitido ao vivo, sobre um tema específico] e por meio delas aprendemos sobre os aplicativos Google. Muitas vezes, sinto-me frustrada. Vejo que os alunos não estão aprendendo da forma que deveriam... recebo atividades malfeitas, sujas e percebo uma regressão. Por outro lado, mães desabafam que o filho(a) não quer fazer e ela não sabe como explicar. Algumas vezes fazemos ligações incentivando. A pergunta é sempre a mesma: "prof. que dia a aula vai voltar?" Assim nós seguimos...temos tentado fazer o melhor. Confesso que não me sinto tão preparada como deveria! A forma de avaliar me traz grande preocupação... Este é um ano de muito aprendizado, de sair da zona de conforto e de repensar as práticas! Nada será como antes...
\end{abstract}

Ainda neste grupo, é preciso destacar os trabalhos coletivos e auxílios fornecidos pelos colegas docentes, exemplificados no relato de uma professora do Ensino Fundamental: "meus colegas têm sido meu único apoio emocional para superar as incertezas do momento e me motivar para continuar oferecendo propostas 


\section{F WEM Eltothato

ISSN: 1984-6444 | http://dx.doi.org/10.5902/1984644464258

que a pandemia colocou nas suas vidas pessoais: perdas, medos, tristezas e mudanças não esperadas, nem desejadas. Não foi estranho que uma professora desabafasse a saudades das aulas presenciais: "é bastante difícil planejar porque sinto muita falta de "dar aula". Outra assim resumiu seus sentimentos: "a experiência tem sido angustiante em todos os sentidos devido ao cenário de incertezas quanto ao retorno às atividades presenciais". O sentimento de se encontrar "fora de lugar" e a necessidade de retomar o controle/lugar foi uma tônica nos depoimentos, gerando os encontros e desencontros propostos no título deste artigo. Como descreveu uma professora, ao comentar sobre as reuniões virtuais docentes em sua escola: "os esforços se concentram em debater o retorno ao modelo antigo ou à normalidade". Aquele contexto não estava associado ao "normal" e a retomada presencial era o que, naquele momento, mais se associava ao sonho da normalidade.

\section{Considerações finais}

Em contextos de incertezas e mudanças, uma única afirmação pode ser considerada certeira: ainda não é possível tecer conclusões sobre o tensionamento entre professores e o ERE. Com esse texto, buscamos somar às pesquisas e pesquisadores que têm se debruçado a compreender este fenômeno movente que tem alterado de forma substancial o trabalho docente, os processos de ensinoaprendizagem, as rotinas familiares, a organização dos espaços educativos, a produção de materiais e a própria expectativa de qualidade do ensino. Agreguem-se a isto os desafios impostos aos gestores das escolas e dos sistemas de ensino.

$E$, não menos importante, temos que ter em mente as questões de gênero que envolvem o magistério. Os dados obtidos nesta pesquisa vão ao encontro dos estudos que desvelam a feminização do magistério, principalmente na Educação Básica. Relatório de pesquisa acerca do trabalho na pandemia (ZANONI; BEZERRA; BRIDI, 2020) aponta notórias diferenças da objetivação do trabalho remoto entre os gêneros, pois as relações laborais e as atividades não remuneradas (principalmente domésticas e de cuidados) se sobrepuseram para elas, apontando para "jornadas superextensas de trabalho" (ZANONI; BEZERRA; BRIDI, 2020, p. 86). 


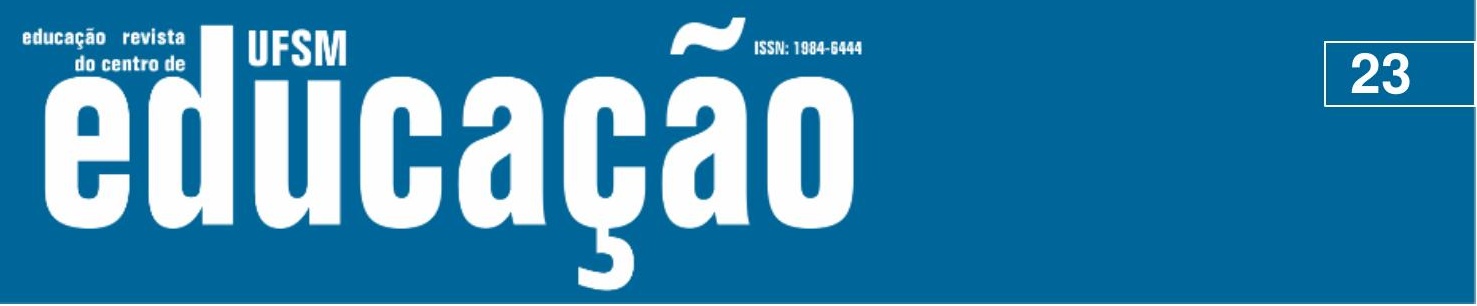

ISSN: 1984-6444 | http://dx.doi.org/10.5902/1984644464258

Encontros e desencontros variados se forjaram neste cenário. Por outro lado, não podemos deixar de apontar que naturalizar as dinâmicas forjadas precipitadamente neste modelo tende a retirar, muito rapidamente, o complemento "emergencial" do "ensino remoto" e com ela, quiçá, as próprias noções de universidade, escola e docência como as conhecemos.

\section{Referências}

BRASIL. Portaria no 544, de 16 de junho de 2020. Dispõe sobre a substituição das aulas presenciais por aulas em meios digitais, enquanto durar a situação de pandemia do novo coronavírus - Covid-19, e revoga as Portarias MEC no 343, de 17 de março de 2020, no 345, de 19 de março de 2020, e n 473, de 12 de maio de 2020. Brasília: Ministério da Educação; Conselho Nacional de Educação, 2020a. Disponível em: https: //cutt.ly/9inmB8v. Acesso em 30 set. 2020.

BRASIL. Parecer CNE/CP no 5/2020, de 28 de abril de 2020. Dispõe sobre a reorganização do Calendário Escolar e da possibilidade de cômputo de atividades não presenciais para fins de cumprimento da carga horária mínima anual, em razão da Pandemia da COVID-19. Brasília: Ministério da Educação; Conselho Nacional de Educação, 2020b Disponível em: http://portal.mec.gov.br/conselho-nacional-deeducacao/atos-normativos--sumulas-pareceres-e-resolucoes/33371-cne-conselhonacional-de-educacao/85201-parecer-cp-2020. Acesso em 15 out. 2020.

CUNHA, Leonardo Ferreira Farias da; SILVA, Alcineia de Souza; SILVA, Aurênio Pereira da. O ensino remoto no Brasil em tempos de pandemia: diálogos acerca da qualidade e do direito e acesso à educação. Revista Com Censo: Estudos Educacionais do Distrito Federal, Brasília, v. 7, n. 3, p. 27-36, 2020. Disponível em: http://www.periodicos.se.df.gov.br/index.php/comcenso/article/view/924. Acesso em 17 jan. 2020.

HODGES, Charles; MOORE, Stephanie; LOCKEE, Barb; TRUST, Torrey; BOND, Aaron. The Difference Between Emergency Remote Teaching and Online Learning, EDUCAUSE Review [online], 2020. Disponível em https: //er.educause.edu/articles/2020/3/the-difference-between-emergency-remoteteaching-and-online-learning. Acesso em 05 out. 2020.

FIEIRA, Letícia; EVANGELISTA, Olinda; FLORES, Renata. Um "presente de grego" para a educação pública brasileira. Executiva Nacional de Estudantes de Pedagogia [online], 2020. Disponível em: https://exnepe.org/2020/05/04/umpresente-de-grego-para-a-educacao-publica-brasileira/. Acesso em 10 dez. 2020. 


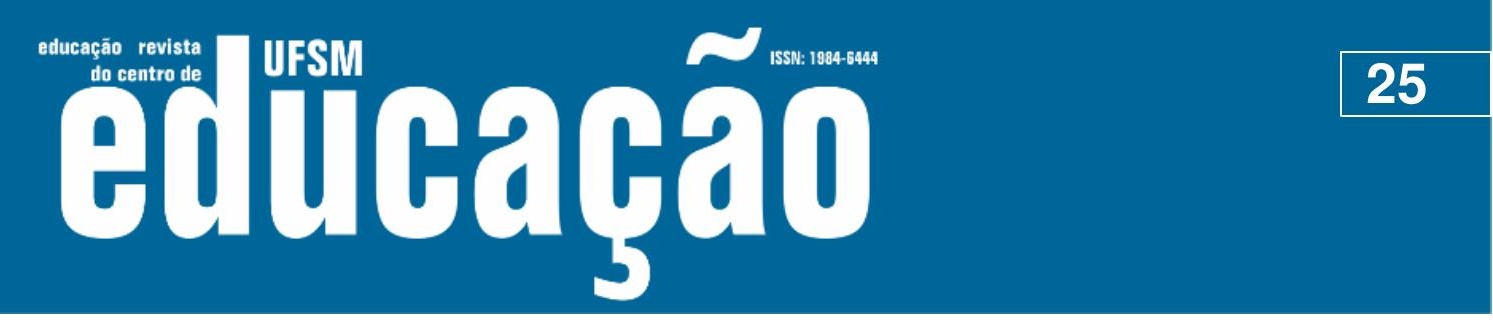

ISSN: 1984-6444 | http://dx.doi.org/10.5902/1984644464258

OLIVEIRA, Raquel; CORRÊA, Ygor; MORÉS, Andréia. Ensino remoto emergencial em tempos de covid-19: formação docente e tecnologias digitais. Revista Internacional de Formação de Professores, v. 5, e020028, 2020. Disponível em https://periodicoscientificos.itp.ifsp.edu.br/index.php/rifp/article/view/179. Acesso 11 out. 2020.

OPAS. Folha informativa COVID-19. Brasília: Escritório OPAS e OMS Brasil, 2020. Disponível em: https://www.paho.org/pt/covid19. Acesso em 15 dez.2020.

PAINEL CORONAVÍRUS. Painel Coronavírus [online], 2020. Disponível em https://covid.saude.gov.br/. Acesso em 15 dez.2020.

PAIXÃO, André. Só 6 das 69 universidades federais adotaram ensino a distância após paralisação por causa da Covid-19. Portal de Notícias G1, [online], publicado em 14/05/2020. Disponível em: https://g1.globo.com/educacao/noticia/2020/05/14/so-6das-69-universidades-federais-adotaram-ensino-a-distancia-apos-paralisacao-porcausa-da-covid-19.ghtml. Acesso em: 15 de out. 2020.

PICHETTI, Caroline. A metamorfose da excepcionalidade. Universidade à Esquerda [online], 2020. Disponível em: https://universidadeaesquerda.com.br/a-metamorfoseda-excepcionalidade-por-carolina-pichetti-nascimento/. Acesso em: 10. dez. 2020.

SARAIVA, Karla, TRAVERSINI, Clarice, LOCKMANN, Kamila. A educação em tempos de COVID-19: ensino remoto e exaustão docente. Práxis Educativa, Ponta Grossa, v. 15, e2016289, p. 1-24, 2020. Disponível em: https://www.revistas2.uepg.br/index.php/praxiseducativa. Acesso em 10 de dez de 2020.

SEMPREVIVA. Sem parar: o trabalho e a vida das mulheres na pandemia. São Paulo: Gênero e Número; Sempreviva Organização Feminista, 2020. Disponível em: http://mulheresnapandemia.sof.org.br/wp-

content/uploads/2020/08/Relatorio_Pesquisa_SemParar.pdf. Acesso em 17 jan. 2021.

SOARES, Sávia Bona. Coronavírus e a modernização conservadora da educação. In: Coronavírus, educação e a luta de classes no Brasil. SOARES, Sávia Bona (Org.). Brasil: Terra Sem Amos, $2020 . \quad$ p. 05-14. Disponível em: https://terrasemamos.files.wordpress.com/2020/05/coronavc3adruseducac3a7c3a3o-e-luta-de-classes-no-brasil-2.pdf. Acesso em 15 out. 2020.

STANGER, Allison. Make All Courses Pass/Fail Now. Chronicle of Higher Education [online], 2020. Disponível em: https://www.chronicle.com/article/Make-All-CoursesPass-Fail-Now/248281. Acesso em 15 out. 2020. 
